\title{
Study of Thyroid Dysfunction in Postpartum Psychosis
}

\author{
Eman M., Khedr' ${ }^{1}$, Ehab S. Ramadan ${ }^{2}$, Emad Farah $\mathbf{M}^{3}$, Mostafa A. Bastawy and M. Nemr Osman ${ }^{4}$. \\ ${ }^{1}$ Department of Neuropsychiatry, Faculty of Medicine, Asuit University, \\ ${ }^{2}$ Department of Neuropsychiatry, Faculty of Medicine, Tanta University, ${ }^{3}$ Department of Clinical Pathology, ${ }^{4}$ \\ Department of Neuropsychiatry, Faculty of Medicine, Aswan University \\ Corresponding author: M. Nemr Osman, Mobile: 01223341551, Email: nemrmohamed@ yahoo.co.uk
}

\begin{abstract}
Background Becoming a mother of newborn involves adaptation to may changes socially and physiologically. Some risk factors are responsible for the development of postpartum psychosis including postpartum hormonal changes.

Objectives: was to study the role of thyroid dysfunction in development of early postpartum psychosis among a sample of Egyptian women.

Subjects and Methods: A total of 60 female patients with postpartum psychosis during the first four weeks after delivery not suffering from any previous psychiatric disorders (Case Group) and 30 female patients within the first four weeks after delivery not suffering any psychiatric disorders (Control Group) were subjected to clinical psychiatric assessment using structured psychiatric interview of DSM -V, BPRS, HDRS and measuring plasma level of thyroid hormones e.g., free triiodothyronine, free tetra-iodothyronine and thyroid stimulating hormone.

Results: There were higher significant difference regarding thyroid dysfunction in patients with postpartum psychosis than in controls. Patients with postpartum psychosis with thyroid dysfunction have a higher significant score on BPRS and HDRS than patients with postpartum psychosis without thyroid dysfunction.

Conclusion: There is significant association between thyroid dysfunction in first four weeks after delivery and postpartum psychosis.
\end{abstract}

Keywords: Thyroid Dysfunction, Postpartum psychosis.

\section{INTRODUCTION}

Becoming a mother of newborn involves adaptation to great changes socially and physiologically. The normal postpartum period consists of sleep deprivation, physical exhaustion, and dramatic hormonal and electrolytes changes. These changes can induce variety of psychiatric disorders, of which postpartum psychosis is the most severe one ${ }^{1}$.

Postpartum psychosis occurs in 1 to 2 of every 1000 new mothers. When undiagnosed and untreated, it presents a danger to both the life of the infant and mother.

Infanticide is rare but does occur in 1 of 250,000 women with postpartum psychosis ${ }^{2}$.

The early symptoms of postpartum psychosis is often a combination of clouding consciousness and mood symptoms. Perplexity, hallucinations, confusion, and sleepiness are common. All these psychotic symptoms have been described among women with puerperal psychosis in the literature: suspiciousness concerning the identity of the child, verbal hallucinations, delusions about the child being a changeling, paranoia, thought broadcasting, echo phenomena, catatonia and mania. Some risk factors are responsible for the development of postpartum psychosis including hormonal, obstetric variables, psychological stressors as well as sociodemographic, genetic, and immunological factors. Some literatures have proposed that the sudden postpartum hormonal changes after childbirth trigger the onset of postpartum psychosis.

Postpartum rapid change in serum levels of many hormones occurs ${ }^{4}$. Postpartum autoimmune thyroid dysfunction (AITD) is defined by autoimmune inflammation and elevated thyroid antibody titers, occurring within the first year after delivery. After delivery prevalence of 5-7\% in the general population, autoimmune thyroid disease has been identified as a risk factor for postpartum psychosis and mood disorders ${ }^{5}$.

In spite of evidence of emerging consensus regarding the link between autoimmune thyroid disorder and postpartum depression, the lower incidence of postpartum psychosis has thus far precluded analogous studies. Although case reports have documented the link of postpartum psychosis and postpartum AITD ${ }^{6}$.

Stewart ${ }^{7}$ in his only previous systematic study found no evidence for an increase of AITD in patients with a late onset of postpartum psychosis. However, no previous study has demonstrated prospective thyroid dysfunction screening in patients with early onset of postpartum psychosis ( 28 days postpartum) before the start of medication.

\section{AIM OF THIS WORK}

Was to study the role of thyroid dysfunction in occurrence of postpartum psychosis within four weeks after delivery in a sample of Egyptian females suffering from postpartum psychosis.

\section{SUBJECTS AND METHODS}

This study was carried out at the out-patient clinic of Neuropsychiatry Department, the outpatient and inpatient of Gynecological and Obstetric Department and Clinical Pathology Department of Aswan University Hospital. 
It was carried out from January 2016 to January 2017. The subjects of this study were females in postpartum period within four weeks after delivery with age ranged from 16 years to 32 years old with a mean age 19.2 years.

\section{Ethical approval}

The study was approved by the medical ethics committee of Aswan University Hospital and a written informed consent is obtained from all patients.

The subjects were grouped into:

- Group I (Case group): Included 60 females with first-onset psychiatric illness developed in the first four weeks after delivery.

\section{- Exclusion criteria:}

- Patients with established neurological disorders and severe physical illness.

- Patients with past history of reported psychiatric illness.

- Patients on hormonal preparations for endocrinal disturbance or any causes.

- Patients with chronic medical illness as renal or hepatic illness.

Patients with history of head trauma and epilepsy.

- Group II (Control group): Included 30 females in the first four weeks after delivery not suffering from any psychiatric disorders.

Exclusion criteria: The same as Group I.

The study was approved by the medical ethics committee of Aswan University Hospital and a written informed consent is obtained from all patients.

\section{The two groups will be subjected to:}

1. Clinical study: Thorough clinical psychiatric examination and clinical assessment by structured psychiatric interview of DSM-V (Diagnostic and Statistical Manual of Mental Disorder 5th ed.) (American Psychiatric Association, 2013).

\section{Laboratory investigations: Serum hormonal assays:}

(A)- A $10 \mathrm{ml}$ blood sample was collected via venipuncture from the antecubital space using vacutainer tube.

The blood was immediately centrifuged, and the serum was separated and stored at $-25 \mathrm{C}^{\circ}$ for subsequent assay. Serum level of thyroid hormones (free T3, T4, TSH) were assayed by automated competitive immunoassay direct chemiluminescence using the VIDAS FT3 kit (Biomeriex SA Corporation) with range of 1.8-4.6 pg/ml., VIDAS FT4 kit (Biomeriex
SA Corporation) with range of 0.93-1.79 ng/dl., VIDAS TSH kit (Biomeriex SA Corporation) with range of $0.25-5.0 \mathrm{IU} / \mathrm{ml}$.

Abnormal results of the three hormones were considered thyroid dysfunction.

(B) Routine laboratory investigations: regarding blood sugar, urea, creatinine, CBC and liver functions.

\section{Psychometric Assessment included Hamilton Rating} Scale for depression (HAM-D OR HDRS), Hamilton, 1967) and Brief Psychiatric Rating Scale (BPRS) Expanded Version (4.0) (2005).

\section{Statistics:}

Statistical presentation and analysis of the present study was conducted, using the mean, standard Deviation, Unpaired Student T-test was used to compare between tow groups in quantitative data and chi-square are computed for $2 \times 2$ tables in qualitative data and Linear Correlation coefficient was used for detection of correlation between two quantitative variables in one group by IBM SPSS Statistics for Windows, Version 20.0.

Armonk, NY: IBM Corp). >0.05 Nonsignificant $<0.05 *$ significant $<0.001 * *$ High significant).

\section{RESULTS}

This study demonstrated that: there was higher significant difference regarding mean score of Brief Psychiatric Rating Scale (BPRS) between patients $($ mean $=76.2-\mathrm{SD} \pm 1.2)$ and controls (mean $=24.9-$ SD \pm 2.0 ) and also higher significant difference regarding mean score of Hamilton Depression Rating Scale between patients with postpartum psychosis $($ mean $=12.6-\mathrm{SD} \pm 1.9)$ and controls $($ mean $=5.33$ $\mathrm{SD} \pm 2.41)$ (Table 1).

There was higher significant difference regarding thyroid dysfunction in patients with postpartum psychosis than in controls and non-significant difference regarding the type of thyroid dysfunction in patients with postpartum psychosis (whether hypo or hyper function) (Table 2).

Patients with postpartum psychosis with thyroid dysfunction have a higher significant score on Brief Psychiatric Rating Scale (BPRS) than patients with postpartum psychosis without thyroid dysfunction (Table 3).

Patients with postpartum psychosis and thyroid dysfunction have a higher significant score on Hamilton Depression Rating Scale (HDRS) than patients with postpartum psychosis without thyroid dysfunction (Table 4). 
ejhm.journals.ekb.eg

Table (1): Mean score of B P R S and HDRS among patients and controls.

\begin{tabular}{|c|c|c|c|c|c|}
\hline & \multirow{2}{*}{$\begin{array}{l}\text { Patients }(\mathbf{n}=60) \text { Mean } \\
\text { SD } \pm\end{array}$} & \multirow{2}{*}{\multicolumn{2}{|c|}{$\begin{array}{l}\text { Controls }(\mathbf{n}=\mathbf{3 0}) \text { Mean } \\
\mathrm{SD} \pm\end{array}$}} & \multicolumn{2}{|c|}{ T-test } \\
\hline & & & & $\mathbf{t}$ & P-value \\
\hline BPRS & 76.2 & 24.9 & 2.0 & 11.334 & $<0.001 * *$ \\
\hline HDRS & 12.6 & 5.33 & 2.41 & 9.342 & $<0.001 * *$ \\
\hline
\end{tabular}

Table (2): The distribution of thyroid dysfunction among patients and controls.

\begin{tabular}{|l|c|c|c|c|c|c|}
\hline \multirow{2}{*}{} & \multicolumn{2}{|c|}{ Patients $\mathbf{( n = 6 0 )}$} & \multicolumn{2}{c|}{ Controls $\mathbf{( n = 3 0 )}$} & \multicolumn{2}{c|}{ Chi-square } \\
\cline { 2 - 7 } & No. & $\mathbf{\%}$ & No. & $\mathbf{\%}$ & $\mathbf{X}^{\mathbf{2}}$ & P-value \\
\hline Normal thyroid function & 49 & 81.7 & 29 & 96.7 & \multirow{2}{*}{3.894} & \multirow{2}{*}{$0.048^{*}$} \\
\hline Thyroid dysfunction & 11 & 18.3 & 1 & 3.3 & & \multirow{2}{*}{0.460} \\
\hline Hypofunction & 7 & 11.7 & 1 & 3.3 & \multirow{2}{*}{0.545} & \multirow{2}{*}{ Hyperfunction } \\
\hline
\end{tabular}

Table (3): Relation between thyroid dysfunction and severity of symptoms rated by Brief Psychiatric Rating Scale (B P R S) among patients with postpartum psychosis

\begin{tabular}{|c|c|c|c|c|}
\hline 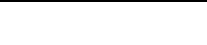 & \multirow{2}{*}{$\begin{array}{l}\text { Patients with } \\
\text { postpartum psychosis } \\
\text { and thyroid } \\
\text { dysfunction }(\mathrm{n}=11)\end{array}$} & \multirow{2}{*}{$\begin{array}{l}\text { Patients with } \\
\text { postpartum psychosis } \\
\text { without thyroid } \\
\text { dysfunction. }(n=49)\end{array}$} & \multicolumn{2}{|c|}{ T-test } \\
\hline & & & $\mathbf{t}$ & P-value \\
\hline Mean BPRS & 80.6 & 74.3 & \multirow{2}{*}{4.165} & \multirow{2}{*}{$<0.001 * *$} \\
\hline SD & \pm 4.2 & \pm 4.6 & & \\
\hline
\end{tabular}

Table (4): Relation between thyroid dysfunction and severity of depressive symptoms rated by Hamilton Depression Rating Scale (HDR S) among patients

\begin{tabular}{|c|c|c|c|c|}
\hline & \multirow{2}{*}{$\begin{array}{l}\text { Patients with postpartum } \\
\text { psychosis and thyroid } \\
\text { dysfunction }(\mathrm{n}=11)\end{array}$} & \multirow{2}{*}{$\begin{array}{l}\text { Patients with postpartum } \\
\text { psychosis without thyroid } \\
\text { dysfunction. }(n=49)\end{array}$} & \multicolumn{2}{|c|}{ T-test } \\
\hline & & & $\mathbf{t}$ & P-value \\
\hline Mean HDRS & 18.4 & 9.4 & \multirow{2}{*}{19.724} & \multirow{2}{*}{$<0.001 * *$} \\
\hline SD & \pm 1.2 & \pm 1.4 & & \\
\hline
\end{tabular}

\section{DICUSSION}

In this study Brief Psychiatric Rating Scale (BPRS) was used in the assessment of symptoms in patients with postpartum psychosis. The mean score of rating scale (BPRS) among patients was 76.2(SD \pm 4.9 ) which was significantly higher than controls (18.2 and $\mathrm{SD} \pm 2.0$ ).

This agreed with Thippeswamy et al. ${ }^{8}$ who reported higher significant score of BPRS in patients with postpartum psychosis. In this study there was higher significant difference regarding the score of Hamilton Depression Rating Scale (HDRS) between patients with postpartum psychosis and controls. Also, Kamperman et al. ${ }^{9}$ reported variable degrees of depressive symptoms in most of their patients than controls. This was in agreement with Jones et al. ${ }^{10}$, Bergink et al. ${ }^{11}{ }_{-}^{12}$, and Lusskin et al. ${ }^{13}$ who reported prevalence of mild to moderate depressive symptoms in patients with postpartum psychosis.

This study reported significant thyroid dysfunction in cases with postpartum psychosis (18.1\%) in comparison to controls $(3.33 \%)$ and there was non-significant difference regarding the type of thyroid dysfunction whether hyperthyroid dysfunction $(6.66 \%)$ or hypothyroid dysfunction (11.66\%) in patients with postpartum psychosis.
This was in agreement with Bergink et al. ${ }^{14}$ who studied thyroid dysfunction in patients with early postpartum psychosis (within four weeks after delivery) in females with first onset psychosis compared with normal controls within 28 days after delivery.

They reported higher significant difference regarding thyroid dysfunction in $19 \%$ of patients with postpartum psychosis in comparison to $5 \%$ in controls. Also, Bokhari et al. ${ }^{6}$ reported link of postpartum psychosis and postpartum thyroid dysfunction due to thyroiditis and Brockington ${ }^{15}$ demonstrated thyrotoxicosis as a risk factor for postpartum psychosis.

In some cases, the postpartum psychotic condition may exacerbate an underlying postpartum thyroiditis. Conversely, in some cases postpartum thyroiditis may serve as an important risk factor, leading to either psychosis, depression or mania depending upon the patient's neurobiological vulnerability ${ }^{16}$.

This study also reported that patients with postpartum psychosis who had thyroid dysfunction (18.3\%) had significant higher mean score on Brief Psychiatric Rating Scale (BPRS) than patients with postpartum psychosis who not having thyroid dysfunction $(81.7 \%)$. 
This means that the severity of symptoms in patients with postpartum psychosis with thyroid dysfunction were more than the severity of the symptoms in patients with postpartum psychosis without thyroid dysfunction.

This study also reported that the patients with postpartum psychosis who had thyroid dysfunction (18.3\%) had more severe depressive symptoms rated on Hamilton Depression Rating Scale (HDRS) than patients with postpartum psychosis without thyroid dysfunction (81.7\%). This agreed with Bergink et al. ${ }^{11}$ in their study on patients with thyroid dysfunction and postpartum psychosis.

In contrast, the only study by Stewart et al. ${ }^{7}$ found no evidence for an increase thyroid dysfunction in patients with late onset postpartum psychosis (more than four weeks after delivery).

So, thyroid dysfunction may play an important role as a risk factor for causation of postpartum psychosis, therefore every women with postpartum psychosis should be screened for thyroid functions. ${ }^{11}$

\section{REFERENCES}

1. Zhong QR, Gelaye B, Fricchione GL, Avillach et al. (2018): Advevsive obstetric and neonatal outcomes complicated by psychosis among pregnant women. BMC Pregnancy Childbirth, 18:1750-0.

2. Vanderkraik R, Barreix M (2017): The global prevalence of postpartum psychosis: A systemic review. BMC. Psychiatry, 17:272.

3. Jones I, Craddock N (2014): Bipolar disorder, affective psychosis and schizophrenia in pregnancy and postpartum period. Lancet, 384:1789-1799.

4. Kumar C, McIvo RJ, Davies T, Brown N, Papadopoulos A, Wieck A et al. (2003): Estrogen administration does not reduce the rate of recurrence of affective psychosis after childbirth. J. Clin. Psychiatry, 64(2):112-8.

5. Kashyap AS, Anand KP, Kashyap S (2004): Postpartum psychiatric disorders. Lancet, 363(9414):1077-8.
6. Bokhari R, BhataraVS, Bandettini F, McMillin JM (1998): Postpartum psychosis and postpartum thyroiditis. J. Psychoneuroendocrinology, 23(6):643-50.

7. Stewart DE, Addison AM, Robinson GE, Joffe R, Burrow GN, Olmsted MP (1988): Thyroid function in psychosis following childbirth. Am. J. Psychiatry, 145(12):1579-81.

8. Thippeswamy H, Berthoud L, Ventura J, Merlo MC (2018): The Brief Psychiatric Rating Scale (version 4.0) factorial structure and its sensitivity in the treatment of outpatients with unipolar depression. Psychiatry research, 210(2):626-33.

9. Kamperman AM, Veldman, HMJ, Wesselook K L (2017): Phynotypal characteristics of postpartum psychosis. Bipolar Disorder. 19:450-457.

Ach.Womens Mental Health, 20:55-59.

10. Jones I, Smith C (2009): Puerperal psychosis: identifying and caring for women at risk. Advances in Psychiatric Treatment, (15):411-418.

11. Bergink V, Kushner SA, Pop V, Kuijpens H et al. (2011): Prevalence of autoimmune thyroid dysfunction in postpartum psychosis. Br. J. Psychiatry, 198(4):264-8.

12. Bergink V, Rasqon $N$ Wisner KL (2016): Postpartum psychosis: madness, mania and melanocholia. Am. J. Psyciat., 137(12)1175-1188.

13. Lusskin S, Stefen M, Richard H (2011): Postpartum psychosis; epidemiology clinical manifestations and assessment. Up Todate inc. Relese .,25.2-c25.112.

14. Bergink V, Pop VJM, Nielsen M E (2018): Comorbidity of autoimunthyroid disorders and psychiatric disorders during the postpartum period. Psychological Med., 48:1291-1298.

15. Brockington IF (2017): Non-reproductive triggers of postpartum psychosis. Ach.Womens Mental Health, $62: 7076$.

16. Vonk R, van der Schot AC, Kahn RS, Nolen WA, Drexhage, HA (2007): Is autoimmune thyroiditis part of the genetic vulnerability (or an endophenotype): for bipolar disorder? Biol Psychiatry, 62(2):135-40 